\title{
A potential low cost adsorbent for the removal of cationic dyes from aqueous solutions
}

\author{
Md. Tamez Uddin ${ }^{1}$ Md. Arifur Rahman ${ }^{1} \cdot$ Md. Rukanuzzaman ${ }^{1}$ • \\ Md. Akhtarul Islam ${ }^{1}$
}

Received: 5 March 2015/ Accepted: 10 February 2017/Published online: 3 March 2017

(c) The Author(s) 2017. This article is published with open access at Springerlink.com

\begin{abstract}
This study was aimed at using mango leaf powder (MLP) as a potential adsorbent for the removal of methylene blue (MB) from aqueous solutions. Characterization of the adsorbent was carried out with scanning electron microscopy, Fourier transform infrared spectroscopy, and nitrogen adsorption-desorption analysis. The $\mathrm{pH}$ at the point of zero charge of the adsorbent was determined by titration method and was found a value to be $5.6 \pm 0.2$. Batch studies were performed to evaluate the influence of various experimental parameters like initial solution $\mathrm{pH}$, contact time, initial concentration of dye and adsorbent dosage on the removal of MB. An adsorptiondesorption study was carried out resulting the mechanism of adsorption was carried out by electrostatic force of attraction. The adsorption equilibrium time required for the adsorption of MB on MLP was almost $2 \mathrm{~h}$ and $85 \pm 5 \%$ of the total amount of dye uptake was found to occur in the first rapid phase $(30 \mathrm{~min})$. The Langmuir and Freundlich isotherm models were used for modeling the adsorption equilibrium. The experimental equilibrium data could be well interpreted by Langmuir isotherm with maximum adsorption capacity of $156 \mathrm{mg} / \mathrm{g}$. To state the sorption kinetics, the fits of pseudo-first-order and pseudo-secondorder kinetic models were investigated. It was obtained that the adsorption process followed the pseudo-second-order rate kinetics. The above findings suggest that MLP can be effectively used for decontamination of dye containing wastewater.
\end{abstract}

Md. Tamez Uddin

mtuddin-cep@sust.edu; mtuddin_cep@yahoo.com

1 Department of Chemical Engineering and Polymer Science, Shahjalal University of Science and Technology, Sylhet 3114, Bangladesh
Keywords Adsorption - Mango leaf powder - Methylene blue $\cdot \mathrm{pH} \cdot$ Isotherms $\cdot$ Kinetics

\section{Introduction}

Many industries, such as textiles, cosmetics, leather, pulp mills, printing, dye synthesis, foods and plastics industries widely use dyes as coloring agents. The removal of color from effluents discharged from these industries is of great concern from the environmental viewpoint because most of these dyes are toxic, mutagenic and carcinogenic (Joshi et al. 2008). Dyes, even in low concentrations, are visually detected and affect the aquatic life and food web. The discharge of colored wastes into receiving streams not only affects the esthetic nature but also interferes with transmission of sunlight into streams and therefore hinders photosynthesis in aquatic plants (Kagalkar et al. 2010). In the present study, methylene blue (MB) has been chosen as a model dye. Methylene blue is a basic dye of thiazine group and is also known as swiss blue and tetramethyl thionine. It appears as a dark green powder that yields a blue solution when dissolved in water. MB has wide applications including cottons or wools dyeing, paper coloring, temporarily coloring hair, and coating for paper stock (Wu et al. 2009). Although not strongly hazardous, it can cause some harmful effects in humans such as heartbeat increase, vomiting, shock, cyanosis, jaundice, quadriplegia, and tissue necrosis. Hence, their removal from industrial effluents before discharging into the environment is extremely important.

The methods of color removal from industrial effluents include coagulation, floatation, biological treatment, filtration, oxidation and adsorption. Among them, liquid 
phase adsorption techniques have proved to be an excellent method to treat dye containing wastewater due to its low initial cost, flexibility, simplicity of design, ease of operation and insensitivity to toxic pollutants (Ahmad et al. 2015; Uddin et al. 2009a, b; Jain and Shrivastava 2008). Due to its effectiveness and versatility, activated carbon is widely employed in water and wastewater treatment. However, the operating cost of activated carbon as adsorbent is high. In addition, problems of regeneration and difficulty in separation from the wastewater after use are another two major concerns of using this material. These have led many researchers to search for more cheap and viable alternative adsorbents.

The use of natural biomaterials is a promising alternative due to their relative abundance and their low commercial value. The research works on various low-cost alternative adsorbents derived from agricultural waste or natural materials for dye removal from aqueous solutions have been reviewed intensively (Sanghi and Verma 2013; Bharathi and Ramesh 2013; Rafatullah et al. 2010; Gupta 2009; Crini 2006; Sanghi and Bhattacharya 2002; Allen and Koumanova 2005). Recently, a nice review on the application of chitosan and its derivatives as adsorbents for dye removal from water and wastewater has been presented (Vakili et al. 2014). Another review has been presented regarding the use of date palm as a potential adsorbent for wastewater treatment (Ahmad et al. 2015). Among different low cost botanic materials used as adsorbents, jackfruit leaf powder (Uddin et al. 2009a, b), gulmohar plant leaf powder (Ponnusami et al. 2009), grapefruit peel (Saeeda et al. 2010), orange peel (Mansour et al. 2012), Ashoka leaf powder (Gupta et al. 2012), water hyacinth leaves (Coronilla et al. 2015), Platanus orientalis leaf powder (Peydayesh and Kelishami 2015), date palm leaves (Gouamid et al. 2013), and banana peel (Mohammed and Chong 2014) have been shown to give satisfactory results in the removal of different dyes from aqueous solution.

Mango (Mangifera indica) is widely cultivated in the tropical and subtropical countries of the world. Bangladesh is one of the major mango producing countries along with India, Pakistan, Mexico, Brazil, the Philippines, etc. Mango trees grow widely throughout Bangladesh and are raised mostly as homestead plantations. Bangladesh produced about 1047849 metric tons of mangoes from an area of about 32011 hectares (Barua et al. 2013). With the production of mango fruits, tons of mango leaves are produced annually. Fallen leaves of mango trees are in great supply, inexpensive and easily available. These leaves have no commercial usage and are not eaten by livestock. Moreover, the waste leaves results in environmental pollution. Hence, the utilization of mango leaves as an adsorbent to remove dyes from industrial effluent can greatly reduce the amount of waste produced. To the best of our knowledge, there are no previous published reports on the use of these leaves for the removal of dyes from aqueous solution. So, the mango leaves as a low-cost and abundant biosorbent could be an alternative for the removal of dyes from wastewater.

The main objective of the present study was to assess the potentiality of mango leaf powder (MLP) as a low cost adsorbent for the removal of MB from aqueous solution in batch system. The effects of different parameters including solution $\mathrm{pH}$, biosorbent dosage, initial dye concentration and contact time were studied. Additionally, the isotherm and kinetic parameters were explored to describe the experimental data.

\section{Materials and methods}

\section{Preparation of adsorbent}

Matured mango leaves were collected from local area near the campus of Shahjalal University of Science and Technology, Sylhet, Bangladesh. The leaves were then repeatedly washed with tap water and subsequently with distilled water to remove all the dirt and earthy materials. The washed leaves were allowed to dry first at room temperature for several days and then in an oven at $105{ }^{\circ} \mathrm{C}$ overnight. The dried leaves were then grounded with grinder and powder leaves were then dispersed in distilled water followed by boiling the water to remove coloring components of the leaves. After boiling, the powder was dried at $105{ }^{\circ} \mathrm{C}$ for $24 \mathrm{~h}$ and sieved to obtain the particle size in the range of $75-300 \mu \mathrm{m}$ and stored in a plastic bottle for use as an adsorbent.

\section{Preparation of dye solutions}

MB (basic blue 9, C.I. 52015; chemical formula, $\mathrm{C}_{16} \mathrm{H}_{18-}$ $\mathrm{N}_{3} \mathrm{SCl}$, MW, $319.85 \mathrm{~g} / \mathrm{mol}$ ) was used as a model cationic dye for this experiment. MB (Merck) was purchased from local supplier and was used as received without further purification. MB stock solution was prepared by dissolving an accurately weighed amount of $\mathrm{MB}$ in distilled water to achieve a concentration of $1000 \mathrm{mg} / \mathrm{L}$. The experimental solutions of desired concentration were prepared by diluting stock solution with suitable volume of double-distilled water. The $\mathrm{pH}$ of solution was maintained at a desired value by adding $0.1 \mathrm{M} \mathrm{NaOH}$ or $\mathrm{HCl}$ solution.

\section{Characterization of adsorbent}

The chemical composition of the MLP (lignin, hemicelluloses, cellulose, ash and extractive components) was determined following conventional analytical methods 
described elsewhere ( $\mathrm{Li}$ et al. 2004). The MLP samples that have particle size ranging from 75 to 300 mesh were used for this analysis method.

Infrared spectrums of MLP was obtained with Fourier transform infrared (FTIR) spectroscopy (Model: FTIR 2000, Shimadzu, Kyoto, Japan) to investigate the surface functional groups of the adsorbent. About $150 \mathrm{mg} \mathrm{KBr}$ disks containing approximately $2 \%$ of MLP samples was prepared shortly before recording the FTIR spectra in the range of $400-4000 \mathrm{~cm}^{-1}$ and with a resolution of $4 \mathrm{~cm}^{-1}$. The resulting spectra were the average of 16 scans.

Brunauer, Emmett, Teller (BET) specific surface area, total pore volume and average pore size of the MLP was analyzed by nitrogen sorption isotherm $(77 \mathrm{~K})$ measurements. Data were collected using the static volumetric method with an ASAP2010 (Micromeritics) apparatus. Samples were degassed at $120{ }^{\circ} \mathrm{C}$ in vacuum for a time interval long enough to reach a constant pressure $(<10 \mu \mathrm{m}$ $\mathrm{Hg}$ ). Specific surface areas were calculated by applying the BET equation between 0.1 and 0.3 relative pressures. Pore size distributions were evaluated by the Barrett, Joyner, Halenda (BJH) method. The calculation was performed by the Micromeritics software package which uses the recurrent method and applies the Harkins and Jura equation for the multilayer thickness.

Scanning electron micrographs were obtained on a scanning electron microscope (Hitachi Tabletop Microscope TM-1000) to study the surface morphology of MLP. Prior to scanning, the adsorbent was coated with gold using a sputter coater and subsequently the SEM images were taken.

The $\mathrm{pH}$ at the point of zero charge $\left(\mathrm{pH}_{\mathrm{PZC}}\right)$ of the adsorbent in aqueous phase was analyzed by titration method described elsewhere. $0.1 \mathrm{~g}$ adsorbent was taken in $50 \mathrm{ml}$ of $0.1 \mathrm{M} \mathrm{KNO}_{3}$ solution and agitated with magnetic stirrer. Then the $\mathrm{pH}$ of the solution was measured after an equilibrium time of $30 \mathrm{~min}$. The titration was carried out with $0.1 \mathrm{M} \mathrm{NaOH}$ and $0.1 \mathrm{M} \mathrm{HCl}$, respectively.

\section{Adsorption studies}

All the adsorption experiments were carried out by batch technique. Batch adsorption studies were performed at different doses of adsorbent, $\mathrm{pH}$, initial dye concentrations and contact time. For each experimental run, $200 \mathrm{ml}$ of MB solution of known concentration was taken in a $250-\mathrm{mL}$ plastic Erlenmeyer flask and was agitated with a known amount of MLP at room temperature $\left(25 \pm 2{ }^{\circ} \mathrm{C}\right)$ using a flash shaker (Stuart Scientific Co. Ltd. Model SF1, U.K.) at constant oscillation of $350 \mathrm{osc} / \mathrm{min}$ for a desired period of time. Preliminary experiments demonstrated that the equilibrium established in about 120 min of contact time. Longer times gave practically the same uptake. Therefore, a contact time of $120 \mathrm{~min}$ was selected for the entire equilibrium test. At the end of adsorption tests, samples were centrifuged and the concentration of residual $\mathrm{MB}$ in the supernatant solution was analyzed using a UV/VIS spectrophotometer (Shimadzu Model UV-1601) by monitoring the absorbance at a maximum wavelength $\left(\lambda_{\max }\right)$ of $664 \mathrm{~nm}$. Blank experiments with only adsorbent in $200 \mathrm{ml}$ of distilled water were conducted simultaneously at the identical conditions to account for any color leached by the adsorbent and adsorbed by glass containers.

The effect of $\mathrm{pH}$ on the removal of $\mathrm{MB}$ was investigated over the $\mathrm{pH}$ range from 2.5 to 10 . The $\mathrm{pH}$ was adjusted with $0.1 \mathrm{~N} \mathrm{NaOH}$ and $0.1 \mathrm{~N} \mathrm{HCl}$ solutions. In this study, $200 \mathrm{ml}$ of $\mathrm{MB}$ dye solution with a concentration of $50 \mathrm{mg} / \mathrm{L}$ was taken in a plastic Erlenmeyer flask and was agitated with $0.25 \mathrm{~g}$ of MLP. There was no appreciable change in $\mathrm{pH}$ of the solution during adsorption. It was presumed that the change in solution $\mathrm{pH}$ would cause a change in the structure of $\mathrm{MB}$, and consequently, in its adsorption process. The change in the structure of $\mathrm{MB}$ would be detected by the variations in the visible spectra of MB. To verify such possibilities, the effect of $\mathrm{pH}$ on the visible spectra of $\mathrm{MB}$ solution was tested in the absence of adsorbents. As the variation in the spectra at given $\mathrm{pH}$ might be time-dependent, the visible spectra of $\mathrm{MB}$ solution was recorded at the same interval time after the $\mathrm{pH}$ was adjusted. It was found that the absorbance of the spectra was stable in the investigated $\mathrm{pH}$ range $(\mathrm{pH}$ 2.5-10).

The effect of dose of the adsorbent was studied by contacting $200 \mathrm{ml}$ dye solution of initial concentration $100 \mathrm{mg} / \mathrm{L}$ with different amounts of MLP (0.1-0.8 g) till the equilibrium was attained.

The equilibrium isotherms are very important in designing adsorption systems. To estimate the adsorption characteristics of an adsorbent, the adsorption isotherm of that adsorbent with a specific adsorbate is registered. Concentration variation method was used to calculate the adsorption characteristic of adsorbent. It was mainly carried out by selecting an appropriate concentration range of the adsorbate with a fixed mass of adsorbent. Adsorption equilibrium isotherms were performed in a set of Erlenmeyer flasks $(250 \mathrm{ml})$ where $200 \mathrm{~mL}$ solutions of MB dye with different initial concentrations (100, 150, 200, 250, 300 and $350 \mathrm{mg} / \mathrm{L}$ ) were placed in these flasks. Equal mass of $0.25 \mathrm{~g}$ of MLP was added to dye solutions and was agitated at a temperature of $25 \pm 2{ }^{\circ} \mathrm{C}$ for $5 \mathrm{~h}$ to reach equilibrium. The shaking time of $5 \mathrm{~h}$ was sufficiently high for the attainment of adsorption equilibrium. After equilibrium had reached, the concentrations in the samples were analyzed as before. The amount of adsorption at equilibrium, $q_{\mathrm{e}}(\mathrm{mg} / \mathrm{g})$, was calculated using the following equation 
$q_{\mathrm{e}}=\frac{\left(C_{0}-C_{\mathrm{e}}\right) V}{W}$

where $C_{0}$ and $C_{\mathrm{e}}(\mathrm{mg} / \mathrm{L})$ were the liquid-phase concentrations of dye at initial and equilibrium, respectively. $V$ was the volume of the solution (L), and $W$ was the mass of dry adsorbent used (g).

The kinetic experiments were performed using a procedure similar to the equilibrium studies. Kinetic studies were carried out to establish the effect of time on the adsorption process and to quantify the adsorption rate. Adsorption kinetic experiments were carried out by agitating $200 \mathrm{~mL} \mathrm{MB}$ solution of different initial concentrations ranging from 100 to $250 \mathrm{mg} / \mathrm{L}$ with $0.25 \mathrm{~g}$ MLP in a $250 \mathrm{ml}$ plastic Erlenmeyer flask at a temperature of $25 \pm 2{ }^{\circ} \mathrm{C}$. The aqueous samples were taken at different time intervals, centrifuged and the residual concentration of MB in the supernatant solution was analyzed as before. The amount of MB adsorbed at contact time $t(\mathrm{~min}), q_{\mathrm{t}}$ $(\mathrm{mg} / \mathrm{g})$, was calculated using Eq. (2):

$q_{\mathrm{t}}=\frac{\left(C_{0}-C_{\mathrm{t}}\right) V}{W}$

where $C_{\mathrm{t}}(\mathrm{mg} / \mathrm{L})$ was the liquid-phase concentrations of $\mathrm{MB}$ at any time $t$.

A desorption study was carried out by agitating $200 \mathrm{ml}$ solution of methylene blue of $50 \mathrm{mg} / \mathrm{L}$ with $0.25 \mathrm{~g}$ of adsorbent. During adsorption the $\mathrm{pH}$ of the solution was increased gradually from 2.3 to 10 while during desorption the $\mathrm{pH}$ of the solution was decreased gradually from 10 to 2.5. The concentrated $\mathrm{HCl}$ and $\mathrm{NaOH}$ were used to change the $\mathrm{pH}$ so that the change in volume of the solution is negligible.

\section{Results and discussions}

\section{Characterization of adsorbent}

The main components of the MLP determined by chemical analysis are given in Table 1. It is seen that cellulose is the dominant macromolecular component in the MLP, and lignin is the second richest group. According to the results,

Table 1 Chemical composition of mango leaf powder

\begin{tabular}{lr}
\hline Component analysis & $\mathrm{wt} \%$ \\
\hline Extractives & 12.2 \\
Hemicelluloses & 13.3 \\
Lignin & 26.6 \\
Cellulose & 45.2 \\
Ash (wt\%) & 2.7 \\
\hline
\end{tabular}

it can be said that the MLP possess typical lignocellulosic structure which contain - $\mathrm{OH}$ groups as main functional groups.

FTIR spectrum of MLP showed the presence of functional groups responsible for adsorption of dye onto MLP. The FTIR spectra obtained for MLP are shown in Fig. 1. As shown in Fig. 1, the spectra displayed a number of absorption peaks, indicating the complex nature of the material examined. The peaks in the FTIR spectra were assigned to various groups and bonds in accordance with their respective wave number $\left(\mathrm{cm}^{-1}\right)$. The broad band observed at $3435 \mathrm{~cm}^{-1}$ was assigned to the stretching vibrations of $\mathrm{O}-\mathrm{H}$ bond in hydroxyl groups (Azouaou et al. 2010). The $\mathrm{O}-\mathrm{H}$ stretching vibrations occured within a broad range of frequencies indicate the presence of phenols and alcohols, which confirms the presence of cellulose and lignin in the MLP samples. Cellulose and lignin molecules contain- $\mathrm{OH}$ groups, but the phenolic structure is a measure of lignin. The bands observed at $2918 \mathrm{~cm}^{-1}$ were assigned to asymmetric $\mathrm{C}-\mathrm{H}$ bands present in alkyl groups. The peak at $1707 \mathrm{~cm}^{-1}$ was characteristics of carbonyl group stretching of carboxylic acid (Pagnanelli et al. 2010). The peak at $1623 \mathrm{~cm}^{-1}$ was attributed to bending vibration of molecular water (Baig et al. 2010). Band at $1383 \mathrm{~cm}^{-1}$ was attributed to $\mathrm{COO}^{-}$symmetric stretching vibration group (Azouaou et al. 2010). The peaks appeared in the region $1320-1210 \mathrm{~cm}^{-1}$ were assigned to the stretching vibration of $\mathrm{C}-\mathrm{O}$ in carboxylic acid. Thus, the FTIR analysis indicated that the MLP contained functional groups such as OH and $\mathrm{COOH}$ that could be potential adsorption sites for interaction with the cationic MB dye.

SEM images of MLP before and after adsorption are shown in Fig. 2a, b, respectively. The availability of pores and internal surface is clearly displayed in the SEM image of the MLP before adsorption (Fig. 2a), and the coverage of the surface and the pores by the adsorbed methylene blue is shown in Fig. 2b. Basically, the porous structure that appeared in Fig. 2a became blurred because of adsorption of MB as is shown in Fig. $2 b$.

The BET surface area, total pore volume of the pores less than $184 \mathrm{~nm}$ diameter and average pore diameter of the MLP were found to be $4.02 \mathrm{~m}^{2} / \mathrm{g}, 0.007 \mathrm{~cm}^{3} / \mathrm{g}$ and $6.5 \mathrm{~nm}$, respectively.

The surface charge $Q$ of the adsorbent as a function of $\mathrm{pH}$ was calculated from the experimental titration data according to the following equation (Kiefer et al. 1997):

$Q=\frac{1}{w}\left(C_{\mathrm{A}}-C_{\mathrm{B}}-\left[\mathrm{H}^{+}\right]-\left[\mathrm{OH}^{-}\right]\right)$

where, $w$ is the dry weight of adsorbent in aqueous system $(\mathrm{g} / \mathrm{L}) ; C_{\mathrm{A}}$ is the concentration of added acid in aqueous system $(\mathrm{mol} / \mathrm{L}) ; C_{\mathrm{B}}$ is the concentration of added base in aqueous system $(\mathrm{mol} / \mathrm{L}) ;\left[\mathrm{H}^{+}\right]$is the concentration of $\mathrm{H}^{+}$ 


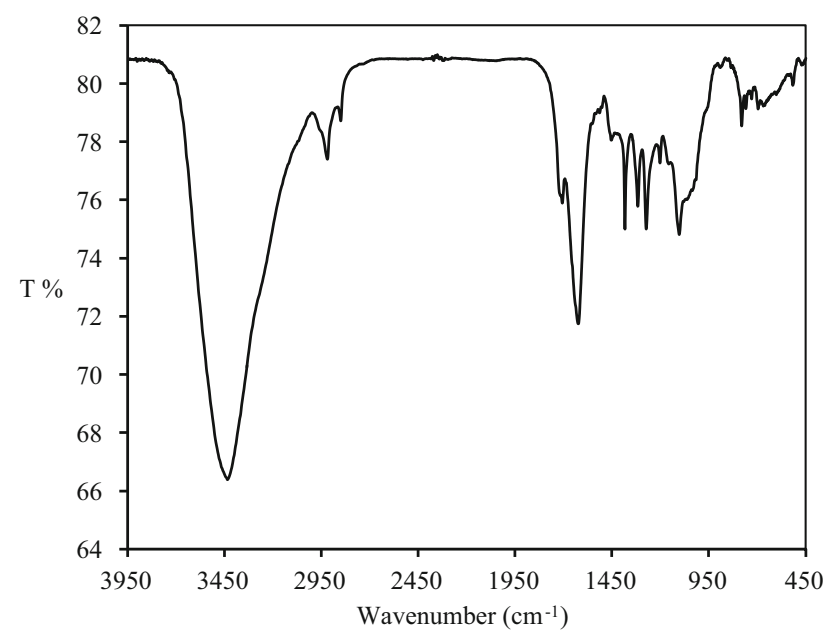

Fig. 1 FTIR spectra of mango leaf powder (MLP)

$(\mathrm{mol} / \mathrm{L}) ;\left[\mathrm{OH}^{-}\right]$is the concentration of $\mathrm{OH}^{-}(\mathrm{mol} / \mathrm{L})$. The $\mathrm{pH}$ value at the point of zero charge was then determined by plotting $Q$ versus $\mathrm{pH}$. Figure 3 shows the surface charge of the adsorbent as a function of $\mathrm{pH}$. The point of zero charge $\left(\mathrm{pH}_{\mathrm{PZC}}\right)$ of the mango leaf powder was estimated to be $5.6 \pm 0.2$.

\section{Adsorption studies}

\section{Effect of pH on adsorption}

The $\mathrm{pH}$ of the dye solution plays an important role in the whole adsorption process and particularly on the adsorption capacity, influencing not only the surface charge of the adsorbent, the degree of ionization of the material present in the solution and the dissociation of functional groups on the active sites of the adsorbent, but also the solution dye chemistry. MB is a cationic dye and it has a pK value of 3.8

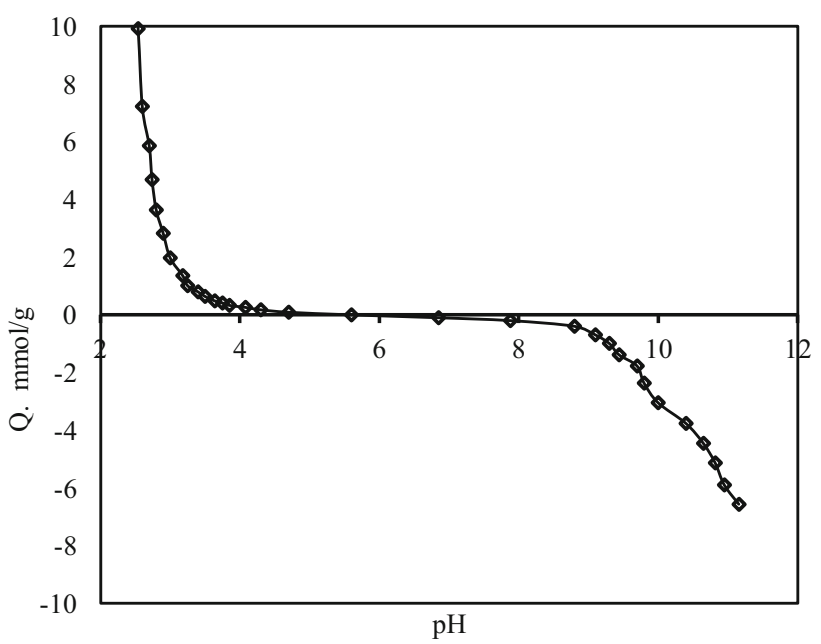

Fig. 3 Surface charge of MLP adsorbent as a function of $\mathrm{pH}$

(Kim et al. 2013). It exists in aqueous solution as positively charged ions at $\mathrm{pH}$ greater than 3.8. As a charged species, the degree of its adsorption onto the adsorbent surface is primarily influenced by the surface charge on the adsorbent, which in turn is influenced by the solution pH. It is commonly known fact that the anions are favorably adsorbed by the adsorbent at lower $\mathrm{pH}$ values due to the presence of $\mathrm{H}^{+}$ions. At high $\mathrm{pH}$ values, cations are adsorbed due to the negatively charged surface sites adsorbents. Figure 4 shows the effect of $\mathrm{pH}$ on the adsorption of methylene blue onto MLP. It was observed that the adsorption capacity was influenced by initial solution $\mathrm{pH}$. The adsorption capacity of MLP was increased from 10.0 to $40.0 \mathrm{mg} / \mathrm{g}$ as the $\mathrm{pH}$ of the dye solution was increased from 2.5 to 10 . This can be explained on the basis of a decrease in competition between positively charged $\mathrm{H}^{+}, \mathrm{H}_{3} \mathrm{O}^{+}$and $\mathrm{MB}$ for surface sites and also by the decrease in positive surface charge on the adsorbent, which results in a lower electrostatic
Fig. 2 SEM images of a raw mango leaf powder and b mango leaf powder after adsorption of MB

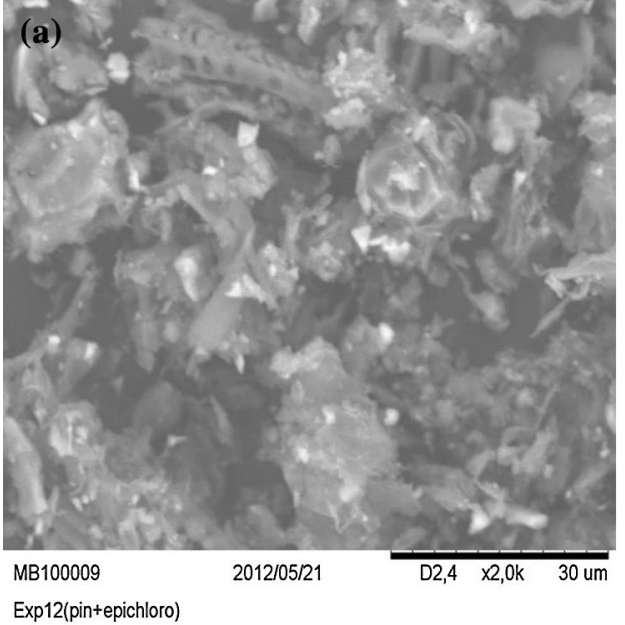

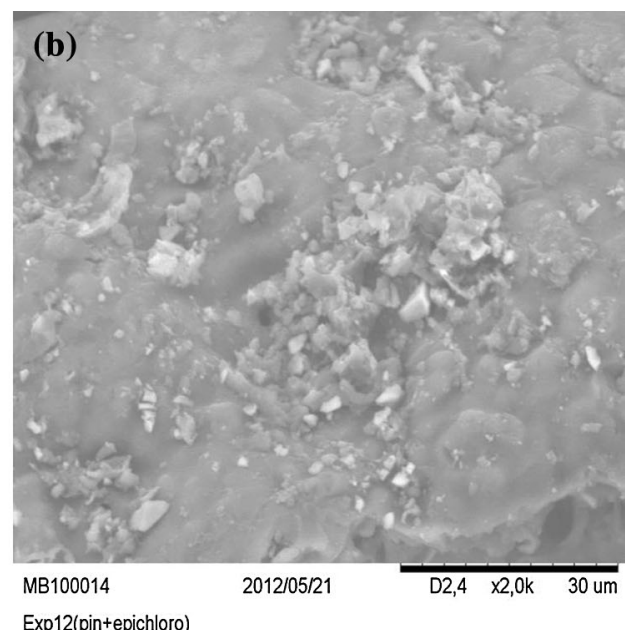

Exp12(pin+epichloro) 
repulsion between the surface and $\mathrm{MB}$. The effect of $\mathrm{pH}$ can also be explained in terms of the zero point of charge $\left(\mathrm{pH}_{\mathrm{PZC}}\right)$ of the adsorbent. The $\mathrm{pH}_{\mathrm{PZC}}$ of MLP was experimentally found to be $5.6 \pm 0.2$. The surface charge of the adsorbent is positive at $\mathrm{pH}>\mathrm{pH}_{\mathrm{PZC}}$, while it is negative at $\mathrm{pH}<\mathrm{pH}_{\text {PZC }}$. Thus, below $\mathrm{pH}$ 5.6, MLP was positively charged and did not favor adsorption of positively charged $\mathrm{MB}$ due to electrostatic repulsion. The optimum $\mathrm{pH}$ for MB biosorption onto MLP was found to be in the range of 7-10 (Fig. 4), which was higher than the $\mathrm{pH}_{\mathrm{PZC}}$ value of 5.6. Thus, the MLP act as a negative surface and attracts the cationic MB resulting higher adsorption capacity.

\section{Effects of adsorbent dose}

The value of equilibrium adsorption capacity $\left(q_{\mathrm{e}}\right)$ and the percentage removal of dye as a function of adsorbent dose are presented in Fig. 5. It was observed that the percentage removal of dye was increased from 82 to $99 \%$ with an increase in adsorbent dose from 0.1 to $0.8 \mathrm{~g}$. The increase in the percentage of dye removal with adsorbent dosages could be attributed to increase in the adsorbent surface areas, augmenting the number of adsorption sites available for adsorption. On the other hand, the adsorption capacity was decreased from 164 to $25 \mathrm{mg} / \mathrm{g}$ when the adsorbent dose was increased from 0.1 to $0.8 \mathrm{~g}$. The decrease in adsorption capacity $q_{\mathrm{e}}(\mathrm{mg} / \mathrm{g})$ with increasing adsorbent dose was due to the split in the flux or the concentration gradient between solute concentration in the solution and the solute concentration in the surface of the adsorbent. Thus, with increasing adsorbent dose, the amount of dye adsorbed onto unit weight of adsorbent was reduced causing a decrease in equilibrium adsorption capacity. Similar adsorption behavior has been reported in case of adsorption of MB on tea waste (Uddin et al. 2009a).

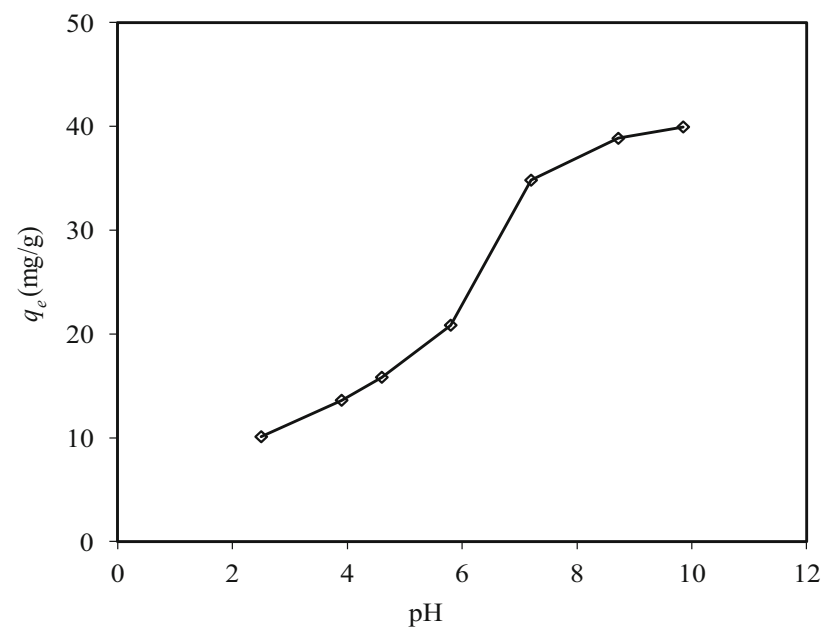

Fig. 4 Effect of $\mathrm{pH}$ on the equilibrium adsorption capacity of $\mathrm{MB}$ onto $\operatorname{MLP}\left(C_{0}=50 \mathrm{mg} / \mathrm{L}, W=0.25 \mathrm{~g}, V=200 \mathrm{~mL}\right)$

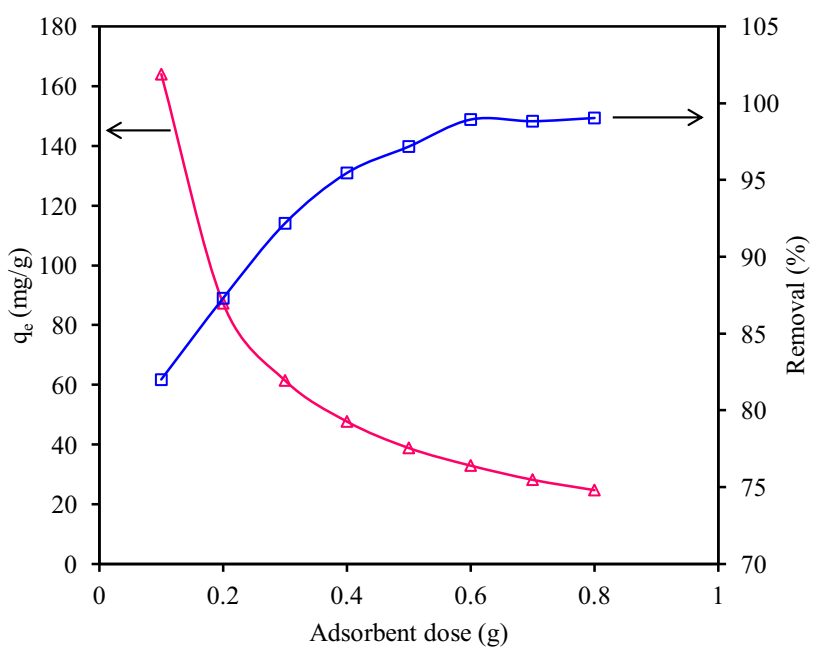

Fig. 5 Effect of adsorbent dose on the adsorption of MB onto MLP $\left(C_{0}=100 \mathrm{mg} / \mathrm{L}, V=200 \mathrm{~mL}\right)$

\section{Effect of contact time and concentration of dye}

To determine proper MB adsorption and equilibrium time, initial concentrations of MB solutions were changed and time intervals were assessed until no adsorption of adsorbate onto MLP took place. The adsorption capacity of MLP for the adsorption of MB versus contact time for various initial concentrations is presented in Fig. 6. The results showed that equilibrium time required for the adsorption of MB on MLP was almost $120 \mathrm{~min}(2 \mathrm{~h})$. However, for subsequent experiments, the samples were left for $4 \mathrm{~h}$ to ensure equilibrium. These results also indicated that $85 \pm 5 \%$ of the total amount of dye uptake was found to occur in the first rapid phase $(30 \mathrm{~min})$ and thereafter the sorption rate was found to decrease. The higher sorption rate at the initial period (first $30 \mathrm{~min}$ ) might be due to an increased number of vacant sites on the adsorbent available at the initial stage resulting increased concentration gradients between adsorbate in solution and adsorbate on adsorbent surface. This increased in concentration gradients tended to increase in dye sorption at the initial stages. As time proceeded, the concentration gradient was reduced due to the accumulation of MB in the vacant sites leading to a decrease in the adsorption rate at the later stages from 30 to 240 min (Vadivelan and Kumar 2005). Figure 6 also showed that the equilibrium adsorption capacity increased with increase in initial MB concentration. The equilibrium adsorption capacity was increased from 79 to $172 \mathrm{mg} / \mathrm{g}$ with increasing MB concentration from 100 to $250 \mathrm{mg} / \mathrm{L}$. This was due to increase in the driving force of the concentration gradient at higher initial dye concentration. When the initial concentrations were increased, the mass transfer driving force became larger resulting in higher adsorption capacity (Tan et al. 2008). 


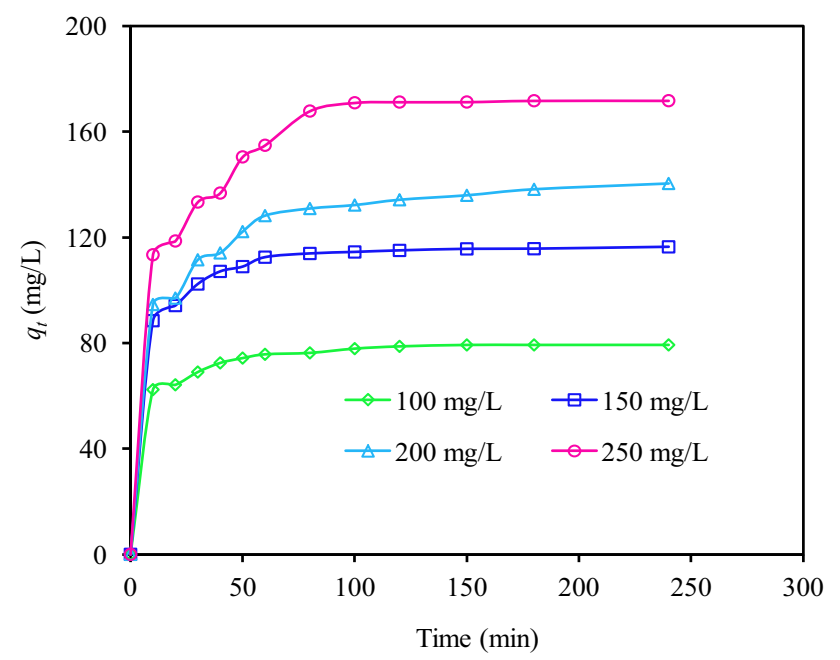

Fig. 6 Effect of contact time and initial concentrations on the adsorption of MB onto MLP $\left(C_{0}=100,150,200,250 \mathrm{mg} / \mathrm{L}\right.$, $W=0.25 \mathrm{~g}, V=200 \mathrm{~mL})$

\section{Adsorption isotherms}

The relationship between the amount of dye adsorbed at constant temperature and its concentration in the equilibrium solution is called the adsorption isotherm. The equilibrium adsorption isotherm is important in the design of adsorption systems. In general, the adsorption isotherms describe how adsorbates interact with adsorbents and are useful for estimating the total amount of adsorbent needed to adsorb a required amount of adsorbate from solution (Jain and Shrivastava 2008). Among different available isotherm equations two important isotherms were selected for this study: the Langmuir and Freundlich isotherms. The applicability of the isotherm equation was compared by judging the correlation coefficients, $r^{2}$.

The Langmuir adsorption isotherm is based on the assumption that all the adsorption sites on the adsorbent surface are energetically equivalent. When the adsorbate occupies a site further adsorption cannot take place at that site and there is no interaction between molecules adsorbed on neighboring sites. The maximum adsorption corresponds to a saturated monolayer of solute molecules on the adsorbent surface. The linear form of Langmuir isotherm can be represented by the following equation (Langmuir 1918):

$\frac{1}{q_{\mathrm{e}}}=\frac{1}{q_{0}}+\frac{1}{q_{0} K_{\mathrm{L}}} \cdot \frac{1}{C_{\mathrm{e}}}$

where $q_{0}$ is the monolayer adsorption capacity $(\mathrm{mg} / \mathrm{g})$ and $K_{\mathrm{L}}$ is Langmuir constants $(\mathrm{L} / \mathrm{mg})$.

The values of $K_{\mathrm{L}}$ and $q_{0}$ were calculated from the slope and intercept of the linear plots of $1 / q_{\mathrm{e}}$ vs. $1 / C_{\mathrm{e}}$ (Fig. 7) and are given in Table 2 . The linearity of plots revealed that the adsorption followed Langmuir isotherm model. The maximum adsorption capacity of MLP for MB was found to be $156 \mathrm{mg} / \mathrm{g}$. For better understanding the adsorption capacity of MLP obtained in this work was compared with other results reported in the literature (Table 3). From Table 3, it was observed that the adsorption capacity of MLP for methylene blue was found to be relatively higher than that of other low cost materials. Therefore, MLP can be used as an effective low cost adsorbent for the treatment of dye bearing wastewaters.

The essential characteristics of the Langmuir isotherm can be expressed in terms of dimensionless constant called separation factor or equilibrium parameter, $R_{L}$, and is given by Eq (5) (Grini 2008):

$R_{\mathrm{L}}=\frac{1}{1+K_{\mathrm{L}} C_{0}}$

where $C_{0}$ is the initial concentration of MB. The value of $R_{\mathrm{L}}$ indicates the type of the isotherm to be either unfavorable $\left(R_{\mathrm{L}}>1\right)$, linear $\left(R_{\mathrm{L}}=1\right)$, favorable $\left(0<R_{\mathrm{L}}<1\right)$ or irreversible $\left(R_{\mathrm{L}}=0\right)$. The calculated $R_{\mathrm{L}}$ values at different initial MB concentrations $(100-350 \mathrm{mg} / \mathrm{L})$ in the present study were found to be in the range of $0.027-0.007$, indicating that MLP was favorable for the adsorption of MB under experimental conditions studied.

Unlike Langmuir isotherm, Freundlich isotherm assumes heterogeneous surface energies, in which the energy term in Langmuir equation varies as a function of the surface coverage. The well-known linearized form of Freundlich isotherm can be expressed as (Freundlich 1906):

$\ln q_{\mathrm{e}}=\ln K_{\mathrm{F}}+\frac{1}{n} \ln C_{\mathrm{e}}$

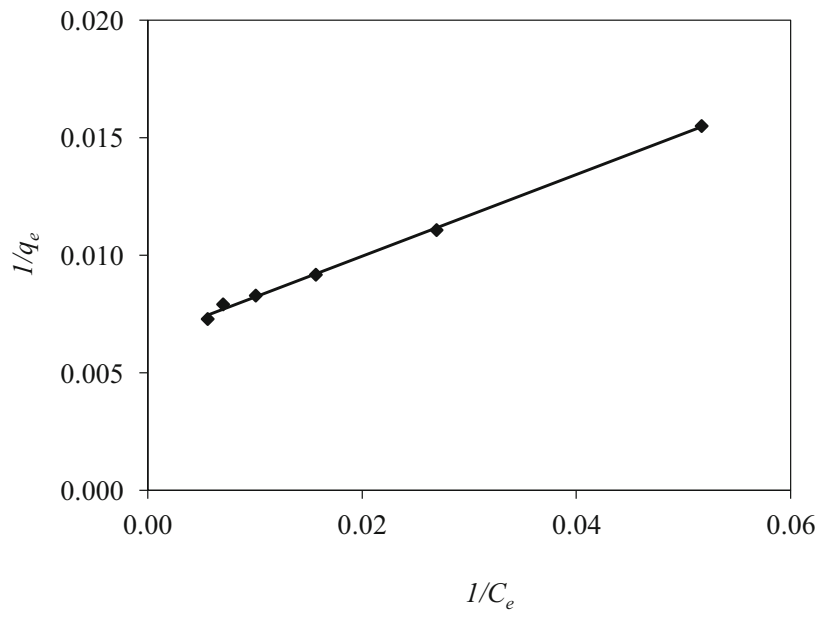

Fig. 7 Langmuir isotherm for adsorption of MB onto MLP $\left(C_{0}=100,150,200,250,300\right.$, and $350 \mathrm{mg} / \mathrm{L}, W=0.25 \mathrm{~g}$, $V=200 \mathrm{~mL}$ ) 
Table 2 Langmuir and Freundlich constants for the adsorption of methylene blue onto MLP

\begin{tabular}{|c|c|c|c|c|c|}
\hline \multicolumn{3}{|c|}{ Freundlich isotherm parameters } & \multicolumn{3}{|c|}{ Langmuir isotherm parameters } \\
\hline$K_{\mathrm{F}}$ & $n$ & $r^{2}$ & $q_{0}(\mathrm{mg} / \mathrm{g})$ & $K_{\mathrm{L}}$ & $r^{2}$ \\
\hline 25.13 & 3.10 & 0.957 & 156 & 0.036 & 0.998 \\
\hline
\end{tabular}

Table 3 Comparison of the adsorption capacity of MB onto maximum monolayer various adsorbents

\begin{tabular}{lll}
\hline Adsorbents & Adsorption capacity $q_{0}(\mathrm{mg} / \mathrm{g})$ & References \\
\hline Raw date pits & 80.3 & Banat et al. (2003) \\
Rice husk & 40.59 & Vadivelan and Kumar (2005) \\
Peanut hull & 68.03 & Gong et al. (2005) \\
Coir pith & 120.43 & Namasivayam et al. (2001) \\
Neem leaf powder & 8.76 & Bhattacharyya and Sarma (2003) \\
Banana peel & 20.8 & Annadurai et al. (2002) \\
Orange peel & 18.6 & Annadurai et al. (2002) \\
Neem saw dust & $2.1-3.6$ & Khattri and Singh (2000) \\
Lemon peel & 29 & Kumar and Porkodi (2006) \\
Palm Kernel fiber & 217.96 & Ofomaja (2007) \\
Neem leaf powder & 8.76 & Sharma and Bhattacharyya (2005) \\
Mango leaf powder & 156 & This study \\
\hline
\end{tabular}

where $K_{\mathrm{F}}$ and $n$ are Freundlich constants with $n$ giving an indication of how favorable the adsorption process. $K_{\mathrm{F}}$ can be defined as the adsorption or distribution coefficient and represents the quantity of dye adsorbed onto MLP for unit equilibrium concentration. The slope of $1 / n$ ranging between 0 and 1 is a measure of adsorption intensity or surface heterogeneity, becoming more heterogeneous as its value gets closer to zero. A value for $1 / n$ below 1 indicates a normal Langmuir isotherm while $1 / n$ above one is an indicative of cooperative adsorption (Fytianos et al. 2000). The plot of $\ln q_{\mathrm{e}}$ versus $\ln C_{\mathrm{e}}$ gave a straight line with slope $1 / n$ (Fig. 8), which showed that the adsorption of MB also followed the Freundlich isotherm. Freundlich constants $K_{\mathrm{F}}$ and $n$ were calculated and also listed in Table 2 .

Table 2 shows the values of the parameters of the two isotherms and the related correlation coefficients. As seen from Table 2, the Langmuir model yielded a somewhat better fit $\left(r^{2}=0.998\right)$ than the Freundlich model $\left(r^{2}=0.957\right)$. As also illustrated in Table 2, the value of $1 /$ $n$ is 0.32 , which indicated favorable adsorption.

\section{Adsorption kinetics}

The prediction of batch adsorption kinetics is necessary for the design of industrial adsorption columns. Kinetic models are used to examine the rate of the adsorption process and

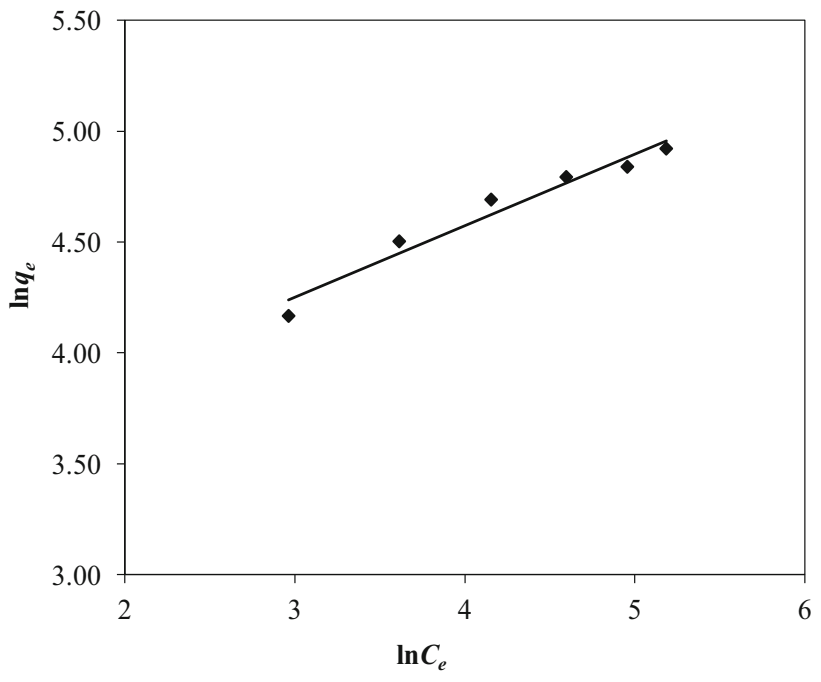

Fig. 8 Freundlich isotherm for adsorption of MB onto MLP $\left(C_{0}=100,150,200,250,300\right.$, and $350 \mathrm{mg} / \mathrm{L}, W=0.25 \mathrm{~g}$, $V=200 \mathrm{~mL}$ )

potential rate-controlling step. In the present work, the kinetic data obtained from batch studies were analyzed using pseudo-first-order and pseudo-second-order models.

The first order equation of Lagergren is generally expressed as follows (Lagergren 1898): 
$\frac{\mathrm{d} q}{\mathrm{~d} t}=k_{1}\left(q_{\mathrm{e}}-q_{\mathrm{t}}\right)$

where $k_{1}$ is the rate constant of pseudo-first-order sorption $\left(\mathrm{min}^{-1}\right)$. The integrated form of Eq. (7) becomes

$\ln \left(q_{\mathrm{e}}-q_{\mathrm{t}}\right)=\ln q_{\mathrm{e}}-k_{1} t$

A plot of $\ln \left(q_{\mathrm{e}}-q_{\mathrm{t}}\right)$ against $t$ should give a linear relationship with the slop of $k_{1}$ and intercept of $\ln q_{\mathrm{e}}$. The plot of linearized form of the pseudo first-order equation is shown in Fig. 9. The pseudo first-order rate constant $k_{1}$, the predicted values, $q_{\mathrm{e}, \mathrm{cal}}$ calculated from the model and the correlation coefficients, $r_{1}^{2}$, are presented in Table 4 . The table shows that the correlation coefficients for pseudofirst-order were low $(<0.96)$ and the predicted values of $q_{\mathrm{e}, \text { cal }}$ were not reasonably close to experimental $q_{\mathrm{e}, \mathrm{exp}}$ values, suggesting the insufficiency of pseudo-first-order model to fit the kinetic data.

The pseudo-second-order kinetic rate equation is expressed as follows (Ho and Mckay (1999):

$\frac{\mathrm{d} q}{\mathrm{~d} t}=k_{2}\left(q_{\mathrm{e}}-q_{\mathrm{t}}\right)^{2}$

where $k_{2}$ is the rate constant of pseudo-second-order sorption $\left(\mathrm{g} \mathrm{mg}^{-1} \mathrm{~min}^{-1}\right)$.The integrated form of Eq. (9) becomes

$\frac{t}{q_{\mathrm{t}}}=\frac{1}{k_{2} q_{\mathrm{e}}^{2}}+\frac{1}{q_{\mathrm{e}}} t$

If the second order kinetic equation is applicable, the plot of $t / q$ against $t$ of Eq. (10) should give a linear relationship. The $q_{\mathrm{e}}$ and $k_{2}$ can be determined from the slope and intercept of the plot, respectively.

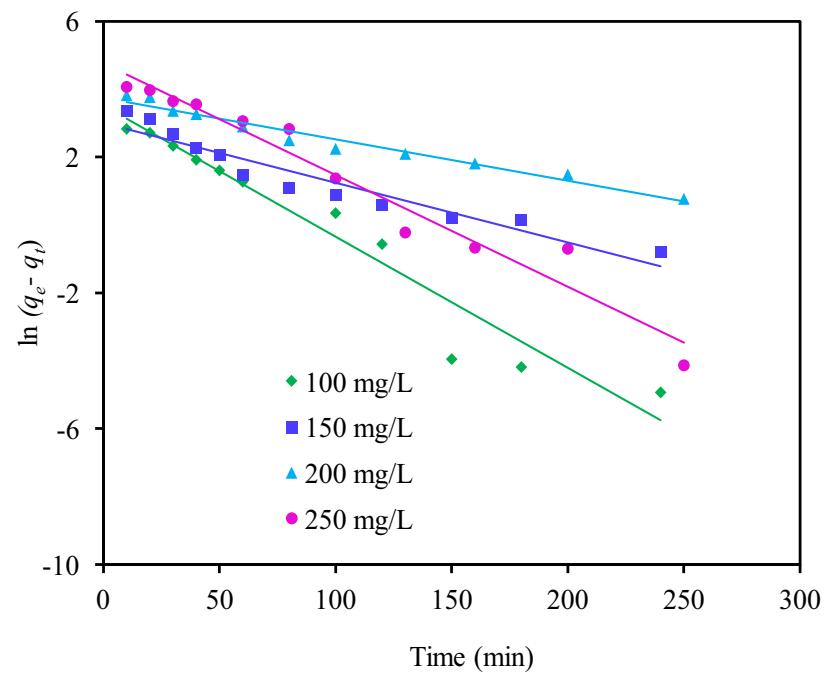

Fig. 9 The pseudo-first-order kinetic plot for adsorption of $\mathrm{MB}$ onto $\operatorname{MLP}\left(C_{0}=100,150,200,250 \mathrm{mg} / \mathrm{L}, W=0.25 \mathrm{~g}, V=200 \mathrm{~mL}\right)$
Figure 10 shows the linearized form of the pseudosecond-order kinetic model. The pseudo-second-order rate constant $k_{2}$, calculated and experimental $q_{\mathrm{e}}$ values and correlation coefficients are also presented in Table 4. As can be seen from Table 4 , the correlation coefficients $\left(r_{2}^{2}\right)$ obtained from pseudo second-order model were found to be higher than 0.998 for all concentrations, which were larger than those of the pseudo first-order model. The results revealed that the pseudo second-order model was the best one in describing the kinetics of MB adsorbed onto mango leaf powder. On the other hand, the calculated values, $q_{\mathrm{e}, \text { cal }}$ obtained from the pseudo-second-order model perfectly agreed with the experimental values, $q_{\mathrm{e}, \exp }$ at all initial concentrations. Hence, it could be concluded that the pseudo-second-order model better represented the adsorption kinetics.

\section{Proposed adsorption mechanism}

For an effective removal of dyes from textile wastewaters, it is essential to understand the mechanism of dye adsorption onto the adsorbents. The adsorption mechanism of MB can be explained by considering the electrostatic interaction between negatively charged surface of MLP and positively charge MB dye. This electrostatic interaction can be explained with the help of surface functional groups of MLP adsorbent and the $\mathrm{pH}$ dependency of the adsorption of MB onto MLP. Fourier transmission infrared spectroscopy (FTIR) analysis confirmed the presence of hydroxyl groups and carboxyl groups on the surface of MLP. The ionization of these groups which depends on solution $\mathrm{pH}$ results in electrical charge on the surface of the MLP adsorbent. The hydroxyl groups and carboxyl groups present on the surface of MLP can gain or lose a proton, resulting in a surface charge that varies with changing $\mathrm{pH}$.

At low $\mathrm{pH}$, MLP surface sites are protonated and surface gets positively charged as shown in Eqs. (11) and (12).

$\mathrm{MLP}-\mathrm{OH}+\mathrm{H}^{+} \rightarrow \mathrm{MLP}-\mathrm{OH}_{2}^{+}$
$\mathrm{MLP}-\mathrm{COOH}+\mathrm{H}^{+} \rightarrow \mathrm{MLP}-\mathrm{COOH}_{2}^{+}$

On the other hand, at high $\mathrm{pH}$, the surface of MLP may get negatively charged due to the reaction of hydroxyl and carboxyl groups with $\mathrm{OH}^{-}$(deprotonation reaction) as shown in Eqs. (13) and (14).

$$
\begin{aligned}
& \mathrm{MLP}-\mathrm{OH}+\mathrm{OH}^{-} \rightarrow \mathrm{MLP}-\mathrm{O}^{-}+\mathrm{H}_{2} \mathrm{O} \\
& \mathrm{MLP}-\mathrm{COOH}+\mathrm{OH}^{-} \rightarrow \mathrm{MLP}-\mathrm{COO}^{-}+\mathrm{H}_{2} \mathrm{O}
\end{aligned}
$$

Thus at high $\mathrm{pH}$, the adsorption process was highly favored through the electrostatic forces of attraction as proposed by Eqs. (15) and (16). 
Table 4 Comparison of the pseudo-first-order, pseudo-second-order adsorption rate constants and calculated and experimental $q_{\mathrm{e}}$ values obtained at different initial MB concentrations

\begin{tabular}{|c|c|c|c|c|c|c|c|}
\hline \multirow[t]{2}{*}{$C_{0}(\mathrm{mg} / \mathrm{L})$} & \multirow[t]{2}{*}{$q_{\mathrm{e}, \exp }(\mathrm{mg} / \mathrm{g})$} & \multicolumn{3}{|c|}{ Pseudo-first-order model } & \multicolumn{3}{|c|}{ Pseudo-second-order model } \\
\hline & & $q_{\mathrm{e}(\mathrm{cal})}(\mathrm{mg} / \mathrm{g})$ & $k_{1}\left(\min ^{-1}\right)$ & $r_{1}^{2}$ & $\begin{array}{l}q_{\mathrm{e}(\mathrm{cal})} \\
(\mathrm{mg} / \mathrm{g})\end{array}$ & $k_{2}(\mathrm{~g} / \mathrm{mg} \min )$ & $r_{2}^{2}$ \\
\hline 100 & 79.3 & 33.7 & 0.038 & 0.94 & 80.6 & 0.0034 & 0.999 \\
\hline 150 & 116.8 & 20.0 & 0.018 & 0.92 & 117.6 & 0.0026 & 0.999 \\
\hline 200 & 140.3 & 42.1 & 0.012 & 0.96 & 140.8 & 0.0011 & 0.998 \\
\hline 250 & 171.7 & 115.5 & 0.018 & 0.95 & 178.5 & 0.0007 & 0.998 \\
\hline
\end{tabular}

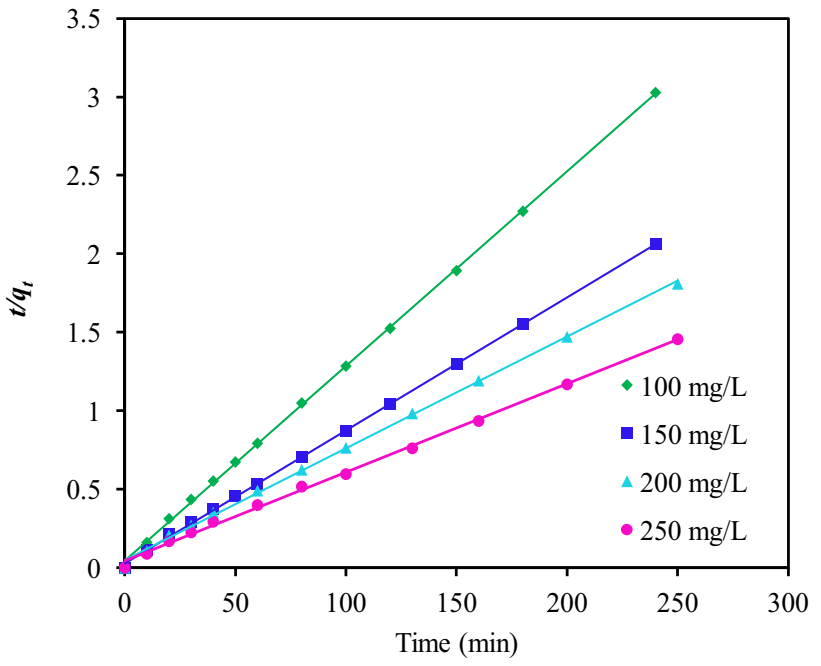

Fig. 10 The pseudo-second-order kinetic plot for adsorption of MB onto MLP at different initial dye concentrations $\left(C_{0}=100,150,200\right.$ and $250 \mathrm{mg} / \mathrm{L}, W=0.25 \mathrm{~g}, V=200 \mathrm{~mL}$ )

$\mathrm{MLP}-\mathrm{O}^{-}+\mathrm{MB}^{+} \rightarrow \mathrm{MLP}-\mathrm{O}^{-\cdots} \mathrm{MB}$

$\mathrm{MLP}-\mathrm{COO}^{-}+\mathrm{MB}^{+} \rightarrow \mathrm{MLP}-\mathrm{COO}^{-\ldots} \mathrm{MB}$

The adsorption of MB by electrostatic attraction was further confirmed by desorption study. Initially the adsorption was observed by increasing the $\mathrm{pH}$ from 2.3 to 10 (Fig. 11). The desorption was then carried out by decreasing the solution $\mathrm{pH}$. Equilibrium concentration of $\mathrm{MB}$ in solution at $\mathrm{pH} 10$ was $1.25 \mathrm{mg} / \mathrm{L}$. The concentration in solution increased from 1.5 to $35.0 \mathrm{mg} /$ $\mathrm{L}$ with the decrease in $\mathrm{pH}$ from 10 to 2.5 (Fig. 11). At lower $\mathrm{pH}$, the protons replace the cationic $\mathrm{MB}$ dye molecules and the protonated surface of the adsorbent became positively charged. Due to this positive charged surface, the repulsion force between the adsorbent surface and dye molecule increased resulting decreased in adsorption as proposed in Eqs. (17) and (18). The increase in $\mathrm{MB}$ concentration in solution with decrease in $\mathrm{pH}$ indicates that the most of dye uptake was carried out by electrostatic force of attraction.

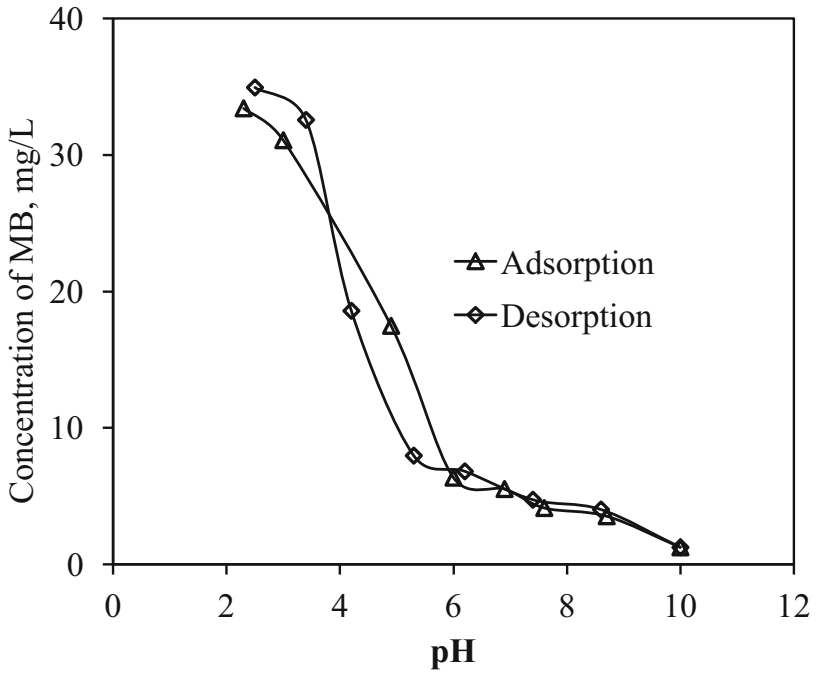

Fig. 11 Adsorption-desorption curve of the methylene blue onto mango leaf adsorbent $\left(C_{0}=50 \mathrm{mg} / \mathrm{L}, W=0.25 \mathrm{~g}, V=200 \mathrm{~mL}\right)$

$\mathrm{MLP}-\mathrm{O}^{-\cdots} \mathrm{MB}+2 \mathrm{H}^{+} \rightarrow \mathrm{MLP}-\mathrm{OH}_{2}^{+}+\mathrm{MB}^{+}$
$\mathrm{MLP}-\mathrm{COO}^{-\cdots} \mathrm{MB}+2 \mathrm{H}^{+} \rightarrow \mathrm{MLP}-\mathrm{COOH}_{2}^{+}+\mathrm{MB}^{+}$

\section{Conclusion}

The ability of MLP to remove MB from aqueous solution was investigated under different experimental conditions in batch mode. Experimental results showed that MLP was effective for the removal of MB from aqueous solutions. The amount of dye adsorbed was found to vary with initial solution $\mathrm{pH}$, initial dye concentrations, contact time, and adsorbent dose. The amount of dye uptake $(\mathrm{mg} / \mathrm{g})$ was found to increase with increasing initial solution concentration and found to decrease with increasing adsorbent dosage. Equilibrium data fitted very well in the Langmuir isotherm equation, confirming the monolayer adsorption of methylene blue onto MLP with a monolayer adsorption capacity of $156 \mathrm{mg} / \mathrm{g}$ which was higher compared to many 
low-cost adsorbents cited in the literature. The kinetics of the adsorption process was found to follow the pseudosecond-order kinetic model. Since MLP used in this work is freely, abundantly and locally available, it can be expected as an economically viable and promising adsorbent for the removal of dyes from aqueous solutions.

Acknowledgements The SUST Research Grant, 2014 for conducting this research work is highly appreciated.

Open Access This article is distributed under the terms of the Creative Commons Attribution 4.0 International License (http:// creativecommons.org/licenses/by/4.0/), which permits unrestricted use, distribution, and reproduction in any medium, provided you give appropriate credit to the original author(s) and the source, provide a link to the Creative Commons license, and indicate if changes were made.

\section{References}

Ahmad A, Setapar SHM, Chuo SC, Khatoon A, Wani WA, Kumar R, Rafatullah M (2015) Recent advances in new generation dye removal technologies: novel search of approaches to reprocess waste water. RSC Adv 5(39):30801-30818

Allen SJ, Koumanova B (2005) Decolourisation of water/wastewater using adsorption (Review). J Univ Chem Technol Metall 40(3): 175-192

Annadurai G, Juang RS, Lee DJ (2002) Use of cellulose-based wastes for adsorption of dyes from aqueous solutions. J Hazard Mater 92(3):263-274

Azouaou N, Sadaoui Z, Djaafri A, Mokaddem H (2010) Adsorption of cadmium from aqueous solution onto untreated coffee grounds: equilibrium, kinetics and thermodynamics. J Hazard Mater 184:126-134

Baig JA, Kazi TG, Shah AQ, Kandhro GA, Afridi H, Khan S, Kolachi NF (2010) Adsorption studies on powder of stem of Acacia nilotica: removal of arsenic from surface water. J Hazard Mater 178:941-948

Banat F, Al-Asheh S, Al-Makhadmeh L (2003) Evaluation of the use of raw and activated date pits as potential adsorbents for dye containing waters. Proc Biochem 39(2):193-202

Barua H, Patwary MMA, Rahman MH (2013) Performance of BARI mango (Mangifera indica L.) varieties in Chittagong region. Bangladesh J Agric Res 38:203-209

Bharathi KS, Ramesh ST (2013) Removal of dyes using agricultural waste as low-cost adsorbents: a review. Appl Water Sci 3:773-790

Bhattacharyya KG, Sarma A (2003) Adsorption characteristics of the dye, Brilliant Green, on Neem leaf powder. Dyes Pigments 57(3):211-222

Coronilla IG, Barrera LM, Urbina EC (2015) Kinetic, isotherm and thermodynamic studies of amaranth dye biosorption from aqueous solution onto water hyacinth leaves. J Environ Manag 152:99-108

Crini G (2006) Non-conventional low-cost adsorbents for dye removal: a review. Bioresour Technol 97:1061-1085

Freundlich HMF (1906) Over the adsorption in solution. Phys Chem 57A:385-470

Fytianos K, Voudrias E, Kokkalis E (2000) Sorption-desorption behavior of 2,4-dichlorophenol by marine sediments. Chemosphere 40:3-6
Gong R, Li M, Yang C, Sun Y, Chen J (2005) Removal of cationic dyes from aqueous solution by adsorption on peanut hull. J Hazard Mater 121:247-250

Gouamid M, Ouahrani MR, Bensaci MB (2013) Adsorption equilibrium, kinetics and thermodynamics of methylene blue from aqueous solutions using date palm leaves. Energy Procedia 36:898-907

Grini G (2008) Kinetic and equilibrium studies on the removal of cationic dyes from aqueous solution by adsorption onto a cyclodextrin polymer. Dyes Pigments 77:415-426

Gupta VK (2009) Application of low-cost adsorbents for dye removal: a review. J Environ Manag 90:2313-2342

Gupta N, Kushwaha AK, Chattopadhyaya MC (2012) Adsorption studies of cationic dyes onto Ashoka (Saraca asoca) leaf powder. J Taiwan Inst Chem Eng 43:604-613

Ho YS, Mckay G (1999) Pseudo-second-order model for sorption process. Proc Biochem 34:451-465

Jain R, Shrivastava M (2008) Adsorptive studies of hazardous dye Tropaeoline 000 from an aqueous phase on to coconut-husk. J Hazard Mater 158(2-3):549-556

Joshi T, Iyengar L, Singh K, Garg S (2008) Isolation, identification and application of novel bacterial consortium TJ-1 for decolorization of structurally different azo dyes. Bioresour Technol 99:7115-7121

Kagalkar AN, Jagtap UB, Jadhav JP, Govindwar SP, Bapat SA (2010) Studies on phytoremediation potentiality of Typhonium flagelliforme for the degradation of Brilliant Blue R. Planta 232(1):271-285

Khattri SD, Singh MK (2000) Colour Removal from synthetic dye wastewater using a bioadsorbent. Water Air Soil Pollut 120:283-292

Kiefer E, Sigg L, Schosseler P (1997) Chemical and spectroscopic characterization of algae surfaces. Environ Sci Technol 31:759-764

Kim R, Santiano B, Kim H, Kan E (2013) Heterogeneous oxidation of methylene blue with surface-modified iron-amended activated carbon. Am J Anal Chem 4:115-122

Kumar KV, Porkodi KJ (2006) Relation between some two- and three-parameter isotherm models for the sorption of methylene blue onto lemon peel. J Hazard Mater 138:633-635

Lagergren S (1898) Zur theorie der sogenannten adsorption geloster stoffe. Kungliga Svenska Vetenskapsakademiens Handlingar 24:1-39

Langmuir I (1918) Adsorption of gases on plain surfaces of glass mica platinum. J Am Chem Soc 40:136-403

Li S, Xu S, Liu S, Yang C, Lu Q (2004) Fast pyrolys is of biomass in free-fall reactor for hydrogen-rich gas. Fuel Process Technol 85:1201-1211

Mansour HF, Gomaa AA, Gamal AM (2012) Potential application of orange peel (OP) as an eco-friendly adsorbent for textile dyeing effluents. J Text Appar Technol Manag 7:1-13

Mohammed RR, Chong MF (2014) Treatment and decolorization of biologically treated Palm Oil Mill Effluent (POME) using banana peel as novel biosorbent. J Environ Manag 132:237-249

Namasivayam C, Radhika R, Suba S (2001) Uptake of dyes by a promising locally available agricultural solid waste: coir pith. Waste Manag 2:381-387

Ofomaja AE (2007) Sorption dynamics and isotherm studies of methylene blue uptake on to palm kernel fibre. Chem Eng J 126:35-43

Pagnanelli F, Viggi CC, Toro L (2010) Development of new composite adsorbents from olive pomace wastes. Appl Surf Sci 256(17):5492-5497

Peydayesh M, Kelishami AR (2015) Adsorption of methylene blue onto Platanus orientalis leaf powder: kinetic, equilibrium and thermodynamic studies. J Ind Eng Chem 25:1014-1019 
Ponnusami V, Gunasekar V, Srivastava SN (2009) Kinetics of methylene blue removal from aqueous solution using gulmohar (Delonix regia) plant leaf powder: multivariate regression analysis. J Hazard Mater 169:119-127

Rafatullah M, Sulaiman O, Hashim R, Ahmad A (2010) Adsorption of methylene blue on low-cost adsorbents: a review. J Hazard Mater 177:70-80

Saeeda A, Sharif M, Iqbala M (2010) Application potential of grapefruit peel as dye sorbent: kinetics, equilibrium and mechanism of crystal violet adsorption. J Hazard Mater 1(79):564-572

Sanghi R, Bhattacharya B (2002) Review on decolorisation of aqueous dye solutions by low cost adsorbents. Color Technol 118:256-269

Sanghi R, Verma P (2013) Decolorisation of aqueous dye solutions by low-cost adsorbents: a review. Color Technol 129:85-108

Sharma A, Bhattacharyya KG (2005) Utilization of a adsorbent based on Azadirachta indica (Neem) leaves for removal of watersoluble dyes. Indian J Chem Technol 12:285-295

Tan IAW, Ahmad AL, Hameed BH (2008) Adsorption of basic dye on high-surface area activated carbon prepared from coconut husk: equilibrium, kinetic and thermodynamic studies. J Hazard Mater 154:337-346

Uddin MT, Islam MA, Mahmud S, Rukanuzzaman M (2009a) Adsorptive removal of methylene blue by tea waste. J Hazard Mater 164(1):53-60

Uddin MT, Rukanuzzaman M, Khan MMR, Islam MA (2009b) Adsorption of methylene blue from aqueous solution by jackfruit (Artocarpus heteropyllus) leaf powder: a fixed-bed column study. J Environ Manag 90(11):3443-3450

Vadivelan V, Kumar KV (2005) Equilibrium, kinetics, mechanism, and process design for the sorption of methylene blue onto rice husk. J Colloid Interface Sci 286(1):90-100

Vakili M, Rafatullah M, Salamatinia B, Abdullah AZ, Ibrahim MH, Tan KB, Gholami Z, Amouzgar P (2014) Application of chitosan and its derivatives as adsorbents for dye removal from water and wastewater: a review. Carbohydr Polym 113:115-130

Wu Y, Zhang L, Gao C, Ma J, Ma X, Han R (2009) Adsorption of copper ions and methylene blue in a single and binary system on wheat straw. J Chem Eng Data 54:3229-3234 